\title{
Inoculation With a Microbe Isolated From the Negev Desert Enhances Corn Growth
}

\author{
Noor Khan', Pilar Martínez-Hidalgo 1,2, Ethan A. Humm ${ }^{1}$, Maskit Maymon', \\ Drora Kaplan ${ }^{3}$ and Ann M. Hirsch ${ }^{1,4 *}$
}

1 Department of Molecular, Cell \& Developmental Biology, University of California, Los Angeles, Los Angeles, CA, United States, ${ }^{2}$ Department of Biology, Geology, Physics and Inorganic Chemistry, Universidad Rey Juan Carlos, Madrid, Spain, ${ }^{3}$ Department of Environmental Hydrology and Microbiology, Zuckerberg Institute for Water Research, Jacob Blaustein Institutes for Desert Research, Ben-Gurion University of the Negev, Beersheba, Israel, ${ }^{4}$ Molecular Biology Institute, University of California, Los Angeles, Los Angeles, CA, United States

Corn (Zea mays L.) is not only an important food source, but also has numerous uses, including for biofuels, fillers for cosmetics, glues, and so on. The amount of corn grown in the U.S. has significantly increased since the 1960's and with it, the demand for synthetic fertilizers and pesticides/fungicides to enhance its production. However, the downside of the continuous use of these products, especially $\mathrm{N}$ and $\mathrm{P}$ fertilizers, has been an increase in $\mathrm{N}_{2} \mathrm{O}$ emissions and other greenhouse gases into the atmosphere as well as run-off into waterways that fuel pollution and algal blooms. These approaches to agriculture, especially if exacerbated by climate change, will result in decreased soil health as well as human health. We searched for microbes from arid, native environments that are not being used for agriculture because we reasoned that indigenous microbes from such soils could promote plant growth and help restore degraded soils. Employing cultivation-dependent methods to isolate bacteria from the Negev Desert in Israel, we tested the effects of several microbial isolates on corn in both greenhouse and small field studies. One strain, Dietzia cinnamea 55, originally identified as Planomicrobium chinense, significantly enhanced corn growth over the uninoculated control in both greenhouse and outside garden experiments. We sequenced and analyzed the genome of this bacterial species to elucidate some of the mechanisms whereby $D$. cinnamea 55 promoted plant growth. In addition, to ensure the biosafety of this previously unknown plant growth promoting bacterial (PGPB) strain as a potential bioinoculant, we tested the survival and growth of Caenorhabditis elegans and Galleria mellonella (two animal virulence tests) as well as plants in response to D. cinnamea 55 inoculation. We also looked for genes for potential virulence determinants as well as for growth promotion.

Received: 09 September 2019

Accepted: 06 May 2020

Published: 19 June 2020

Citation:

Khan N, Martínez-Hidalgo P. Humm EA, Maymon M, Kaplan D and Hirsch AM (2020) Inoculation With a Microbe Isolated From the Negev

Desert Enhances Corn Growth.

Front. Microbiol. 11:1149. doi: 10.3389/fmicb.2020.01149

\section{INTRODUCTION}

Corn (Zea mays L.) belongs to the grass family Gramineae, and is an important food, feed, and fuel crop across the globe, especially in the US Midwest (Butler et al., 2018). Corn is both highly productive and strongly influenced by temperature (Hu and Buyanovsky, 2003; Schlenker and Roberts, 2009; Lobell et al., 2013; Prasad et al., 2018) and salinity (Farooq et al., 2015;

\section{Keywords: corn, Dietzia cinnamea, Negev Desert, plant growth, biosafety}


Iqbal et al., 2018). Therefore, it is critical to develop efficient strategies that improve stress tolerance in this crop and also overcome the significant yield losses predicted to occur under changing soil and climatic conditions. One sustainable solution is to employ plant growth-promoting bacteria (PGPB), which colonize plant roots and improve plant health and growth either directly or indirectly (Backer et al., 2018). Various studies focusing on the beneficial role of PGPB on different crop plants have been published (Vejan et al., 2016; Timmusk et al., 2017; and references therein). However, not all the potentially useful strains that show promise in the laboratory have succeeded in the commercial market mainly because they often lack certain key characteristics that render them abiotic-stress tolerant so that they can persist under challenging environmental conditions. Hence, there is a pressing need for abiotic stress-tolerant PGPB to alleviate the adverse effects of fluctuating conditions in soil.

The present study is a step in that direction. Here, the effects of abiotic stress-tolerant $D$. cinnamea 55 inoculation on the growth and health of corn were evaluated. To our knowledge, this is the first report of growth enhancement in corn mediated by Dietzia cinnamea. This hitherto unrecognized PGPB will be useful for further investigations into replacing synthetic amendments with beneficial bacteria.

\section{MATERIALS AND METHODS}

\section{Screening for Abiotic Stress Tolerance Ability of Negev Desert Isolates}

Various bacteria that were isolated in a joint project between the University of California Los Angeles (USA) and Ben Gurion University of the Negev (Israel) were screened to find abiotic stress-tolerant bacteria with potential for plant growth promotion (PGPB). The details of the sampling sites, isolation procedure, and the media used for cultivation of the bacterial strains have been described (Kaplan et al., 2013). Preliminary screening included the assessment of bacterial strains for their ability to tolerate abiotic stresses by streaking them on Luria-Bertani (LB) agar plates supplemented with $\mathrm{NaCl}(2,4$, and 6\% w/v) to test for salinity stress; PEG (polyethylene glycol; aver. mol. wt. 3,350) at 30,45 , and $60 \%$ for drought stress, and $\mathrm{pH} 4$ and 9 for $\mathrm{pH}$ stress. Media plates that contained neither salt nor PEG at $\mathrm{pH}$ 7.0 served as the controls. The growth of the bacterial strains at high temperature was also assessed by placing a set of streaked plates in a Fisher Scientific Incubator (Model 655D) adjusted to $37^{\circ} \mathrm{C}$. For all the experimental sets, plates incubated at $30^{\circ} \mathrm{C}$ served as the control and bacterial growth was observed over a period of 10 days.

The abiotic stress tolerance of the selected strain was assessed in shake-flask conditions by growing individual bacterial cultures under control $\left(0 \% \mathrm{NaCl}, \mathrm{pH} 7,30^{\circ} \mathrm{C}\right)$, saline $(2,4$, and $6 \% \mathrm{w} / \mathrm{v}$ $\left.\mathrm{NaCl}, \mathrm{pH} 7,30^{\circ} \mathrm{C}\right)$, and drought $(0 \% \mathrm{NaCl}, \mathrm{pH} 7,30,45$, and $60 \%$ PEG $3350,30^{\circ} \mathrm{C}$ ) conditions in $150 \mathrm{ml}$ Erlenmeyer flasks containing $50 \mathrm{ml} \mathrm{LB}$, with an initial inoculum of about $10^{7}$ $\mathrm{CFU} / \mathrm{ml}$. The flasks were incubated in a New Brunswick Scientific Co. (Edison, NJ, United States) Series 25 incubator shaker at $180 \mathrm{rpm}$. Viable cells $(\mathrm{CFU} / \mathrm{ml})$ were counted at various time intervals for up to 15 days by serial dilution plating on LB agar plates in triplicate (Mishra and Nautiyal, 2012).

Physiological characterization of the selected strain was performed for various plant growth promotion abilities including the production of cellulase, pectinase, xylanase, and protease following standard protocols (Khan et al., 2018). Siderophore production and phosphate solubilization activity were tested on CAS agar and PVK plates, respectively, following the methods described by Schwartz et al. (2013).

\section{Amplification, Purification, and Sequencing of the 16S rRNA Gene}

The identification of the bacterial strains was based on phylogenetic and molecular evolutionary analyses (Adhikari et al., 2015). Bacteria were suspended from a single colony grown on LB agar plates into $20 \mu \mathrm{l}$ of sterile distilled water (SDW). The gene for $16 \mathrm{~S}$ rRNA was amplified by PCR using the forward primer $\mathrm{fD} 1$ and the reverse primer $\mathrm{rD1}$ (Weisburg et al., 1991). Amplification was performed in a total volume of $25 \mu \mathrm{l}$ containing $14.9 \mu \mathrm{l}$ SDW, $1 \mu \mathrm{l}$ of bacterial lysate sample, $2.5 \mu \mathrm{l}$ of $10 \times \mathrm{Taq}$ Buffer $\left(\mathrm{MgCl}_{2}\right), 0.5 \mu \mathrm{fD} 1$ and $\mathrm{rD} 1$ $(10 \mu \mathrm{M}), 0.5 \mu \mathrm{l}$ dNTPs $(10 \mathrm{mM}), 5 \mu \mathrm{l} \mathrm{Q}$ solution and 0.125 $\mu 1$ Taq DNA polymerase. Amplified 16S rDNA products were visualized with ethidium bromide both in the gel and in the gel electrophoresis running buffer and purified from a $0.8 \%$ lowmelting point agarose gel $(100 \mathrm{~V}, 400 \mathrm{~mA}, 1 \mathrm{~h})$. The gel extraction was performed with the Invitrogen Quick Gel Extraction Kit according to the manufacturer's directions. The samples were then sent to Laragen Inc. ${ }^{1}$ for further processing and sequencing. The nucleotide sequences were compared against nucleotide databases using the NCBI BLASTn and EzTaxon server 2.1 programs to identify the closest known taxa.

\section{Phylogenetic Analysis}

The 16S rRNA gene along with their closest homology sequences were aligned using multiple sequence alignment program CLUSTAL W algorithm implemented in MEGA 6 software by using default parameters. The phylogenetic tree was constructed by Maximum Likelihood method using the MEGA 6 program and evolutionary distances were computed with the help of Kimura's 2 parameter models. The bootstrap analysis with 1000 replications using $\mathrm{p}$-distance model was performed based on the original dataset to estimate the confidence of a particular clade (Adhikari et al., 2015).

\section{Plant Growth Promotion Analysis Greenhouse Trials}

Greenhouse experiments were conducted in pots with corn plants at the Plant Growth Center, UCLA. Kernels of Zea mays L. (Golden Bantam), obtained from Baker Creek Heirloom Seed Company, Mansfield, MO, United States, were surface-sterilized by immersing them in $70 \%$ ethanol for $1 \mathrm{~min}$, followed by three rinses with SDW. For the treatments, the kernels were bacterized for $3 \mathrm{~h}$ by imbibing them in a bacterial suspension, which had

\footnotetext{
${ }^{1}$ http://www.laragen.com/
} 
been grown for $48 \mathrm{~h}$ to contain approximately $10^{9} \mathrm{CFU} / \mathrm{ml}$. Postimbibition, the kernels had an approximate $10^{6} \mathrm{CFU} / \mathrm{ml}$ adherent bacterial population. Kernels imbibed in LB medium served as the control. The treatments consisted of control and strain 55treated plants grown in sterile Sungro Potting Mix containing mainly Canadian sphagnum peat moss along with a small fraction of coarse perlite and dolomitic limestone. ${ }^{2}$ Eight replicates of each treatment, with four plants in each pot, were prepared. Soil moisture was maintained to approximately $20 \%$ with water. Plants in all the treatments were grown in parallel and harvested at the same time after 45 days of sowing. Measurements on morphological parameters, namely shoot length and root length, were recorded at the time of harvesting, using general methods as described earlier (Nautiyal et al., 2006). Plant dry weight measurements were made after drying the plants in a $60^{\circ} \mathrm{C}$ oven. Photographs of the plants were taken with a Canon PowerShot ELPH350HS camera. The trial was repeated three times and the data were generated from the pooling of all the trials. The data are presented as mean \pm standard deviation (SD). The statistical analysis was performed using GraphPad Prism software version 5.01 (GraphPad Software, San Diego, CA, United States).

\section{Field Studies}

The plant growth stimulatory effect of strain 55 was also examined in an outside garden. As a pilot experiment, a pot trial on the pattern similar to the greenhouse trial was set up and the pots were placed in an open, but protected hoop house for examining whether the corn growth promotion mediated by strain 55 was effective under real-life environmental conditions. On observing a positive response of strain 55 on the growth of corn in the pots, we tested the effectiveness of strain 55 by sowing bacterized and untreated corn kernels directly in the soil of the experimental microplot $(2 \mathrm{~m} \times 2 \mathrm{~m})$ within the confines of the hoop house in an outside garden adjacent to the Plant Growth Center, UCLA, Los Angeles. The corn kernels (var. Golden Bantam) were planted in four rows, two for each treatment. Each row contained 12 plants, with an intra- and inter-row spacing of about 20 and $60 \mathrm{~cm}$. Harvesting was carried out after 120 days of sowing, followed by the recording of the plant data. The outside experiment was repeated three times in all including the pilot experiment, and the data presented results from the pooling of all trials. The data are presented as mean \pm standard deviation (SD). The statistical analysis was performed using GraphPad Prism software version 5.01 (GraphPad Software, San Diego, CA, United States).

\section{Determination of Whether $D$. cinnamea 55 Is Virulent}

Because soil bacteria may express proteins from biochemical pathways with pathogenic potential, strain 55 was monitored for its effects on two animal models, the nematode worm Caenorhabditis elegans and the wax worm, larvae of Galleria mellonella, as well as plants. In addition, the D. cinnamea 55 genome was also examined for the possible presence of virulence genes (Martínez-Hidalgo et al., 2018).

\footnotetext{
${ }^{2}$ http://www.sungro.com/professional-product/sunshine-mix-2/
}

\section{Nematode Assays}

The activity of C. elegans fed with strain 55 under slow-killing conditions was assayed as described by Vílchez et al. (2016). Briefly, the test bacteria were spread on two nematode growth media (NGM) plates and incubated at $30^{\circ} \mathrm{C}$ for $24 \mathrm{~h}$. The NGM plates were prepared following the method of Brenner (1974). Each plate was seeded with a known number of nematodes from the original control plate (Escherichia coli OP50), which was determined using a Zeiss microscope at 10X magnification (Carl Zeiss, Oberkochen, Germany). This number served as a zero-h reading. After counting, the plates were incubated at $25^{\circ} \mathrm{C}$ and scored for nematode death every $24 \mathrm{~h}$ for 5 days. The strain E. coli OP50 served as a control for estimating the natural death rate of the nematodes and Pseudomonas aeruginosa PA14 was the positive control for pathogenicity. The experiment was conducted three times with two replicates of the bacterial strain. The evaluation of the effect of bacteria on C. elegans was conducted based on the pathogenicity score given by Cardona et al. (2005). The authors established that a given strain could be designated pathogenic for the nematode if one of the following criteria were met: (i) a diseased appearance at day 2, which included reduced locomotive capacity and the presence of a distended intestine; (ii) percentage of live nematodes at day $2 \leq 50 \%$; and (iii) total number of nematodes at day $5 \leq 50 \%$. The presence of one, two, or three of these criteria was scored to differentiate mild from severe infections. A pathogenic score (PS 1, 2, or 3) was given based on the number of criteria met. A strain was considered non-pathogenic when no symptoms of disease were observed (pathogenicity score, PS 0). Additionally, the influence of the bacteria on movement and propagation of the nematodes was monitored for $120 \mathrm{~h}$. The data are presented as mean \pm standard deviation (SD). The statistical analysis was performed using GraphPad Prism software version 5.01 (GraphPad Software, San Diego, CA, United States).

\section{Galleria mellonella Virulence and Alfalfa Infection Assays}

Larvae of the insect, G. mellonella (greater wax moth), were also used to investigate the potential virulence of $D$. cinnamea 55. G. mellonella has been used to differentiate pathogens from commensal symbionts via a system that is homologous to mammalian innate immune systems (Lange et al., 2018). The larvae were purchased from Carolina Biological Supply (Burlington, NC) and the wax worms were prepared as described by Joyce and Gahan (2010). Briefly, overnight grown cultures of the bacterial strains were centrifuged at room temperature, rinsed in PBS and resuspended in sterile phosphate buffered saline (PBS) to $1 \mathrm{OD}_{600}$ unit. Ten individual larvae were injected with $10 \mu \mathrm{l}$ of the relevant bacterial suspension using a sterile Hamilton syringe and a 30-gauge disposable needle. The larvae were placed in individual treatment petri-dishes lined with $8.5 \mathrm{~cm}$ Whatman paper, and incubated at room temperature, in the dark. The same number of larvae were injected with PBS alone served as negative controls, while those injected with Pseudomonas aeruginosa PA14 (Jander et al., 2000) were the positive controls. Post inoculation, percent survival of waxworms over a period of 10 days was 
recorded. Three independent replicates of each infection were performed per strain.

In addition, strain 55 was tested in the alfalfa (Medicago sativa) seedling model (Bernier et al., 2003) to verify that no deleterious effects occurred on plants in response to strain 55 inoculation. For the trial, alfalfa seedlings were grown and inoculated with bacterial strains as described by Bernier et al. (2003). Pathogenic Burkholderia cepacia 68P128 was used as a control for assessing the comparison of disease development. Controls included seedlings wounded and inoculated with $10 \mu \mathrm{l}$ of a $0.85 \% \mathrm{NaCl}$ solution. The seedlings were visually monitored for disease symptoms at days 5 and 10 post-infection.

\section{Genome Sequencing and Bioinformatics Information}

Strain 55 cells were grown in $5 \mathrm{ml}$ of $\mathrm{LB}$ at $30^{\circ} \mathrm{C}$ for $18 \mathrm{~h}$ at $180 \mathrm{rpm}$. DNA extractions were performed using Invitrogen's PureLink $^{\mathrm{TM}}$ Genomic DNA Mini Kit. The purified DNA was monitored for integrity by gel electrophoresis, and then sent to the US Department of Energy Joint Genome Institute (JGIDOE) for sequencing as a part of the CSP 1571 project: "The nodule microbiome from legumes living in diverse environments: What other endophytes live within legume nodules besides the nitrogen-fixing symbiont?" The goal of the project was to determine not only the identities of the endophytic bacteria within legume nodules but also bacteria closely associated with the plant rhizosphere that promoted plant growth, especially from an arid environment. The sequencing method used was Illumina Mi Seq, PacBio RS II (Mukhtar et al., in review). Some features of the D. cinnamea 55 genome are presented in Table 4 and Figure 5.

The Dietzia cinnamea 55 genome was queried using IMG/MER ${ }^{3}$ against other sequenced Dietzia species and strains as well as other Gram-positive species including Micromonospora aurantiaca ATCC 27029 and L5 (Hirsch et al., 2013), Bacillus subtilis 30VD-1 (Khan et al., 2018), and B. simplex 30N-5 (Maymon et al., 2015) for plant-growth promoting traits such as phytohormone production, abiotic stress resistance, siderophore synthesis, and salinity tolerance. In addition, we queried the genomes for genes encoding virulence determinants such as the type VII secretion system (T7SS), which is frequently found in Gram-positive microbes, especially pathogenic species.

\section{RESULTS}

\section{Identification of Abiotic Stress-Tolerant Strain 55}

Strain 55 was isolated from rhizosphere soil under the canopy of the dominant plant Zygophyllum dumosum (Kaplan et al., 2013). During the collection period, the total monthly rainfall was low except in January 2010, normally the rainy season, at which time the rainfall increased to $81.2 \mathrm{~mm}$, which is higher than normal. The following year, in February 2011, the rainfall level was only $21.2 \mathrm{~mm}$ indicating that bacteria and plants living in this location have to adapt to significant environmental stress. In addition, the

${ }^{3}$ https://img.jgi.doe.gov/cgi-bin/er/main.cgi temperature in the driest months was $45-50^{\circ} \mathrm{C}$. Based on these parameters, we reasoned that strategies for microbial survival would reflect a high percentage of genes for stress and osmotolerance and hypothesized that bacteria with these traits might serve as potential inoculants under conditions of climate change.

In vitro experiments conducted on plates demonstrated that strain 55 is an efficient salt-, $\mathrm{pH}-$, and drought-tolerant bacterial species compared to the 40 other bacterial isolates tested (data not shown). Molecular characterization based on 16S rDNA sequence analysis of strain 55 indicated that its closest phylogenetic relationship is to Dietzia cinnamea with $99 \%$ homology (Figure 1). A growth curve of strain 55 in presence of 2,4 , and $6 \% \mathrm{NaCl}$ was monitored at $30^{\circ} \mathrm{C}$ for up to 15 days. Strain 55 survived mild salt stress conditions with a final $\mathrm{CFU}$ of $\sim 10^{7-8} \mathrm{CFU} / \mathrm{ml}$ on day 15 . However, a reduced CFU $\left(\sim 10^{5-6} \mathrm{CFU} / \mathrm{ml}\right)$ was observed in $6 \% \mathrm{NaCl}$. A similar trend was recorded in 30, 45, and 60\% PEG over a period of 15 days, where strain 55 exhibited a CFU of $10^{5-6} \mathrm{CFU} / \mathrm{ml}$ for all three concentrations of PEG tested (Supplementary Figure S1). Also, strain 55 was found to be sensitive to higher temperatures because the plates incubated at $37^{\circ} \mathrm{C}$ demonstrated no growth in comparison to the control plates incubated at $30^{\circ} \mathrm{C}$, which showed good growth.

Among the plant-growth promotion attributes that influence endophytic entry into the plant as well as antagonistic behavior against other microbes, strain 55 tested positive for cellulase, xylanase (Supplementary Figure S2), protease, and amylase production, but not for pectin degradation. Biochemical assays for the presence of siderophores and the ability to solubilize phosphate demonstrated that strain 55 performed the former (Supplementary Figure S2), but not the latter (data not shown). These conclusions were confirmed by finding genes that code for the production of siderophores in the strain 55 genome (Table 4), but none for phosphate solubilization.

\section{Adaptations to Stress}

Maize is well adapted to high temperatures but grows poorly if severely stressed by drought. Genes with the potential to confer temperature and desiccation tolerance were predicted to reside in the $D$. cinnamea 55 genome. The genomes of two Grampositive spp. that function as PGPB (Bacillus subtilis 30VD-1 and Micromonospora aurantiaca ATCC $27029^{3}$ ) were used to probe the $D$. cinnamea genome for homologous genes. Possible mechanisms for stress tolerance include the expression of genes for trehalose synthesis and glycine/betaine production, heat shock proteins, and many other functions.

Trehalose, two glucose molecules joined together via an alpha$(1,1)$ glycosidic linkage, is produced by a wide range of organisms and is important for protecting cells from desiccation (Streeter and Gomez, 2006). Genes for three distinct pathways were uncovered in the $D$. cinnamea 55 genome: (1) the MOTS pathway where trehalose synthase (treXYZ genes) converts maltooligosyl saccharides to maltooligosyl trehalose; (2) the TPS pathway where in the first step, trehalose-6-phosphate is synthesized from UDP-glucose and glucose-6-phosphate upon the expression of ots A (trehalose- 6 phosphate synthase) followed by trehalose 6phosphate phosphatase via ots $B$ expression to generate trehalose; 


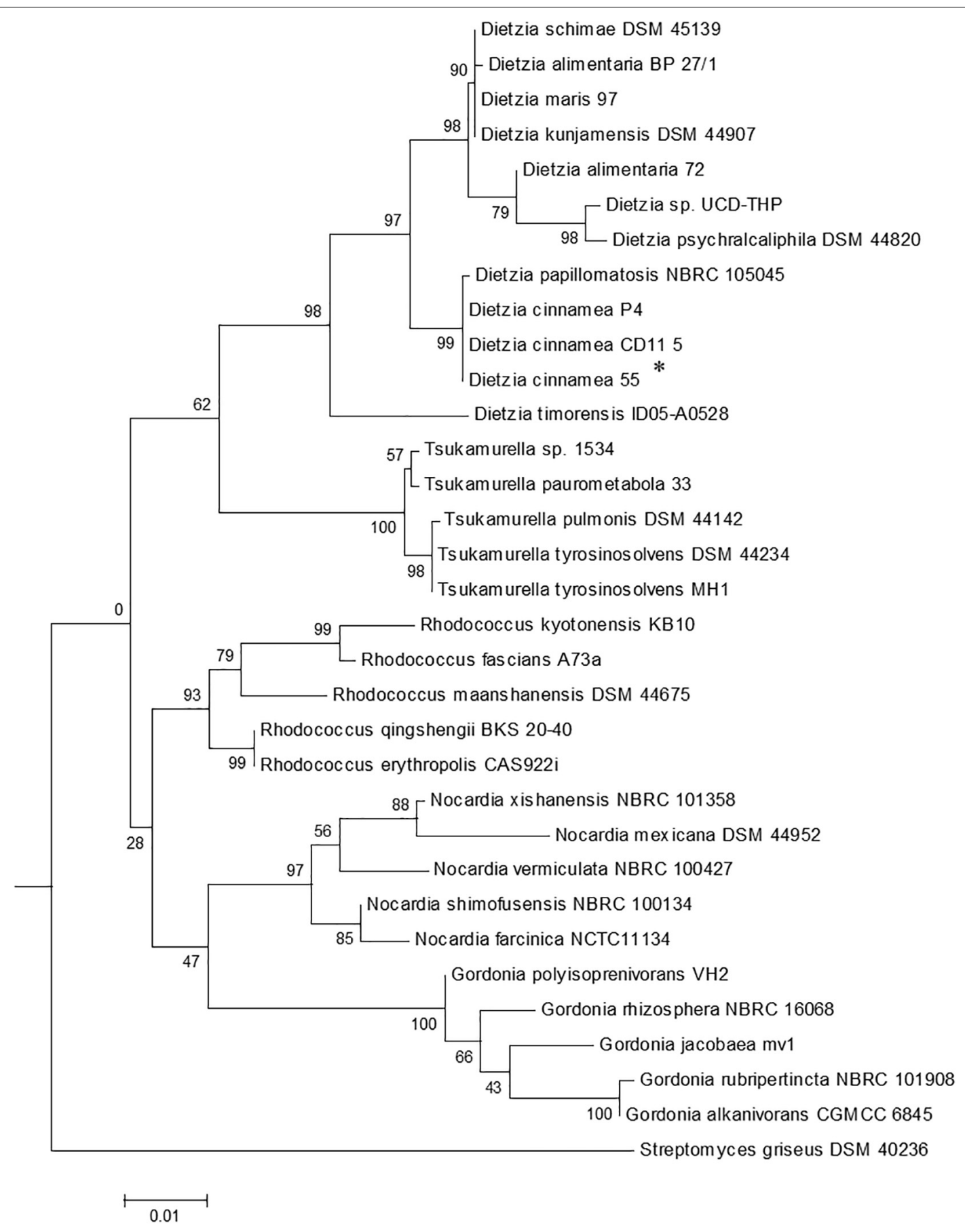

FIGURE 1 | The phylogenetic tree of Dietzia cinnamea 55 was constructed based on 16SrDNA sequences. Bootstrap values are based on 1000 replications. The asterisk indicates the strain for which the 16S rDNA sequence was determined in this study. Bar, 0.01 substitutions per site.

and (3) the synthesis of trehalose from maltose directly via treS (TS: trehalose synthase). For the MOTS pathway in the D. cinnamea 55 genome, ots $B$ was not adjacent to ots $A$ as it is for M. aurantiaca ATCC 27029 (Figure 5), which occurs in Rhizobium and Paraburkholderia spp. (Angus et al., 2013, 2014).

Several genes encoding stress-related proteins including catalase and peroxidase, the universal stress protein A (UspA), and superoxide dismutases were also detected in the $D$. cinnamea 55 genome. In addition, genes encoding proteins for an osmoprotectant transport system were found in the strain 55 genome (Table 4) as well as genes important for biofilm formation such as the tad/pil operon (Pu and Rowe-Magnus, 2018). The biofilm state helps 
plant-associated bacteria tolerate drought stress (Timmusk et al., 2013).

\section{Effect of $D$. cinnamea 55 on the Growth of Corn}

In a greenhouse experiment performed for 45 days, the effect of corn kernel bacterization with strain 55 was assessed in comparison to an untreated control. Plants raised from the treated kernels showed improved overall health that was observed in terms of a significant increase of $\sim 30$ and $16 \%$ in plant parameters, namely shoot and root length as well as a $\sim 70 \%$ increase in dry plant biomass over the untreated controls. Also, more extensive root growth was observed in the strain 55-treated plants in comparison to the control plants (Figure 2 and Table 1). After 35 days, the treated plants (right) exhibited significantly much more root and shoot growth than the control plants.

\section{Outside Garden Studies}

The effect of inoculating strain 55 on corn plant growth was also assessed in outside garden experiments. The field soil was analyzed for basic properties at Waypoint Analytical (Anaheim, CA 92807), and was found to have the following: organic matter $4.24 \%$, Salinity (ECe) $1.7 \mathrm{dS} / \mathrm{m}$, Sodium Adsorption Ratio (SAR) $1.72, \mathrm{pH} \sim 5.5$. The extractable nutrient content of available $\mathrm{N}$, $\mathrm{P}, \mathrm{K}, \mathrm{Ca}, \mathrm{Zn}$, and $\mathrm{Fe}$ was found to be in the optimal range. The effectiveness of the bacterial treatment was evident by the stimulation of plant growth parameters where an increase of 39 and $36 \%$ was recorded in shoot length and plant dry weight of kernels bacterized with strain 55, respectively, as compared to non-bacterized kernels. Also, a $62 \%$ increase in the fresh weight of harvested corn ears was observed for treated plants over the control sets (Figure 3 and Table 2).

\section{Virulence Tests With C. elegans and G. mellonella}

Because several other Dietzia isolates have been considered as potential pathogens based on their origins from immunocompromised patients (Hirvonen et al., 2012), we pursued studies to determine whether or not strain 55 exhibited virulence traits. Assays with the nematode C. elegans are frequently used to analyze broad-host range microbial pathogenicity when $P$. aeruginosa PA14, which is an effective killer of nematodes, is used as a positive control. On NGM, C. elegans exposed to PA14 were motile, but avoided the bacteria, which remained unconsumed by the nematodes, leading to their death (Table 3). In contrast, their normal food source, E. coli OP50, has no effect on worm viability. Similarly, the test strain D. cinnamea 55 did not show any inhibitory effect on the motility and growth of worms (Table 3 and Figure 4A).

The Galleria assay results showed that injection of larvae with $D$. cinnamea 55 did not hamper their development and activity, similar to larvae injected with PBS. On the other hand, the larvae injected with $P$. aeruginosa PA14 showed normal movement until $24 \mathrm{~h}$ and then afterward demonstrated increasing melanization followed by death. On day 10, the percent survival of waxworms injected with P. aeruginosa PA14

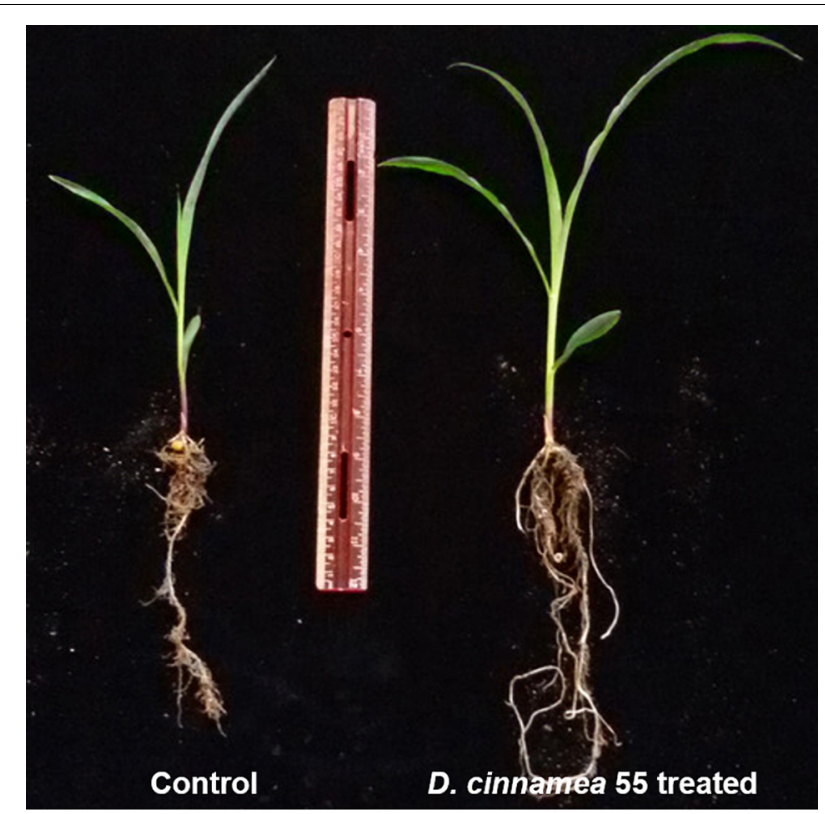

FIGURE 2 | Effect of $D$. cinnamea 55 on the plant growth promotion of corn (Pot trial).

TABLE 1 | Effect of D. cinnamea 55 inoculation on the growth of corn plants (pot trial).

Parameters

Treatments

\begin{tabular}{lcc}
\cline { 2 - 3 } & Control & Treated \\
\hline Shoot length (inches) & $32.08 \pm 4.62^{\mathrm{a}}$ & $41.94 \pm 5.54^{\mathrm{b}}$ \\
Root length (inches) & $16.63 \pm 3.99^{\mathrm{c}}$ & $19.34 \pm 2.49^{\mathrm{d}}$ \\
Dry plant biomass $(\mathrm{g})$ & $10.09 \pm 2.93$ & $17.70 \pm 4.95$ \\
\hline
\end{tabular}

Values are mean of 8 replicates $\pm S D$ of 30 plants in each treatment at the time of harvesting (data recorded after 45 days of experiment setup). Statistical significance of data was validated using One-way ANOVA with Tukey's post hoc test and multiple comparison procedure. Different letters represent values that differ significantly, $P<0.05$. Plant biomass data were statistically evaluated using unpaired $t$-test, $P<0.05$.

was $40 \%$ whereas that of waxworms injected with PBS or D. cinnamea 55 was $100 \%$. Larvae injected with D. cinnamea 55 and PBS did not show any melanization or mortality (Figure 4B and Supplementary Figure S3).

In the alfalfa assay, $60 \%$ of the seedlings treated with B. cepacia $68 \mathrm{P} 128$ demonstrated yellowing and subsequent necrosis after 10 days of infection, while seedlings treated with D. cinnamea 55 remained unaffected like the untreated controls (Figure 4C and Supplementary Figure S3). Also, in some of our greenhouse trials, where sorghum (Sorghum bicolor) and chickpea (Cicer arietinum) seeds were bacterized with D. cinnamea 55, no deleterious effects on plant growth were observed when compared to the control (unpublished data). In addition, we infected wounded onion leaves with strain 55 and B. cepacia 68P128, a known pathogen, as described by Estrada-de los Santos et al. (2018). B. cepacia 68P128-treated leaves exhibited 


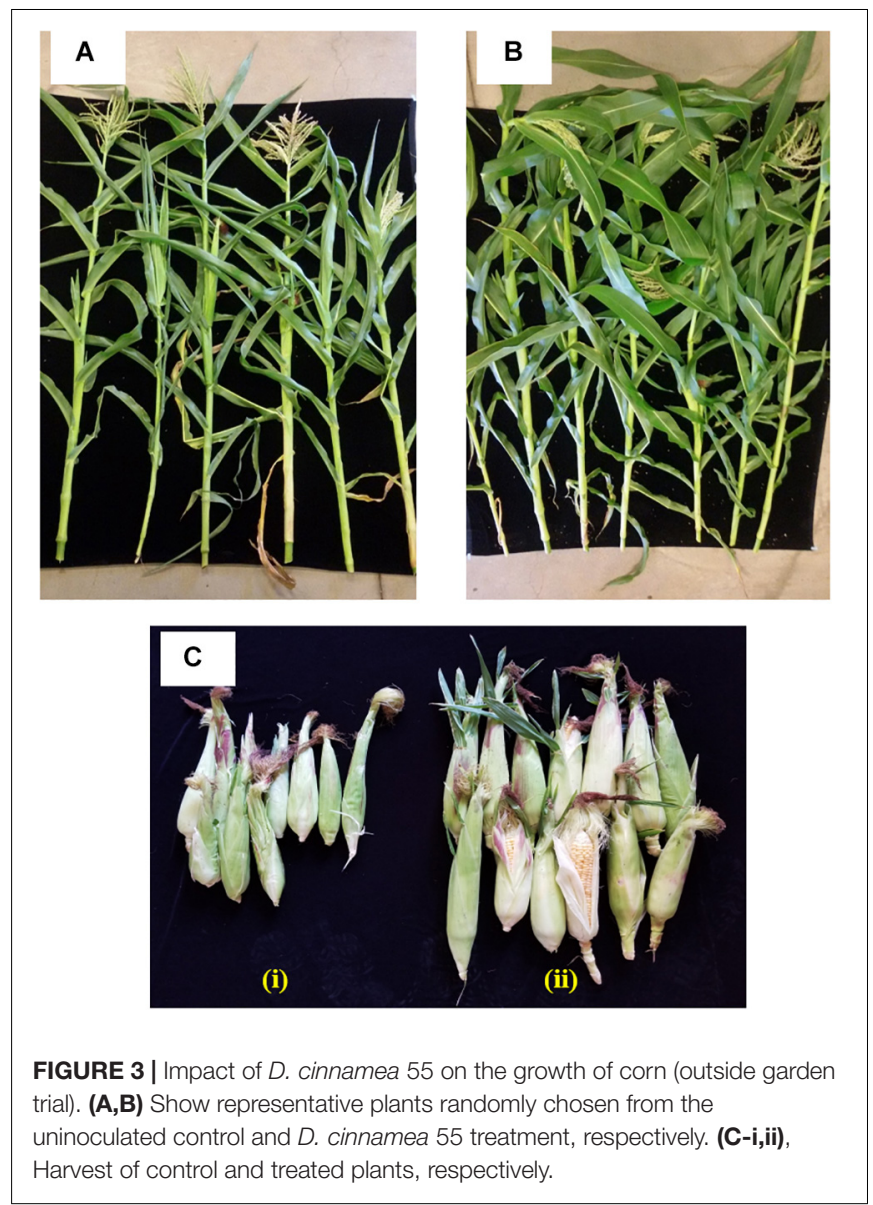

TABLE 2 | Effect of D. cinnamea 55 inoculation on growth of corn (Microplot trial).

\begin{tabular}{|c|c|c|}
\hline \multirow[t]{2}{*}{ Parameters } & \multicolumn{2}{|c|}{ Treatments } \\
\hline & Control & Treated \\
\hline Shoot length (inches) & $33.71 \pm 10.01$ & $47.19 \pm 6.21$ \\
\hline Dry shoot biomass (g) & $29.66 \pm 5.10$ & $40.37 \pm 8.72$ \\
\hline Fresh wt. of 10 cobs (g) & $34.8 \pm 7.63$ & $56.5 \pm 9.73$ \\
\hline Dry wt. of 10 cobs (g) & $17.9 \pm 6.54$ & $37.31 \pm 5.77$ \\
\hline
\end{tabular}

Values are means of 24 plants $\pm S D$ for each of the treatments at the time of harvesting (after 120 days of sowing).

severe browning whereas strain 55 inoculation had no negative effects (unpublished data).

The sequencing of the genome of strain 55 (IMG Genome ID: 2786546145); allowed us to look for gene sequences encoding potential virulence factors. The T3SS and T4SS, which are closely associated with virulence in Gram-negative plant pathogenic microbes, are not found in Gram-positive bacteria. Only one T3SS gene (IMG\#2786720821; Ga0193691_10711) potentially encoding an inner membrane YOP/YscD-like protein and one T4SS gene (IMG\#2786722165; Ga0193691_124300), which if expressed would code for a TraM-binding TradD/TraG-like protein, were detected in the genome. On the other hand, genes
TABLE 3 | Pathogenicity score and behavioral response of $C$. elegans to the bacterial strains.

\begin{tabular}{lccccc}
\hline Strains & PS* $^{*}$ Motility & $\begin{array}{c}\text { Accumulation } \\
\text { in batches }\end{array}$ & $\begin{array}{c}\text { Avoidance of } \\
\text { bacterial lawn }\end{array}$ & $\begin{array}{c}\text { Digestion of } \\
\text { bacterial } \\
\text { lawn }\end{array}$ \\
\hline $\begin{array}{l}\text { Pseudomonas } \\
\text { aeruginosa PA }\end{array}$ & 3 & Very slow & - & Around edge & - \\
14 & & & & & \\
$\begin{array}{l}\text { E. coil OP50 } \\
\text { D. cinnamea 55 }\end{array}$ & 0 & Fast & By $72 \mathrm{~h}$ & - & By $48 \mathrm{~h}$ \\
\hline
\end{tabular}

${ }^{*}$ Pathogenicity score (PS) 0, no indication of disease; 1, 2 and 3, one two or three symptoms of disease, respectively.

for the T7SS are commonly found in Gram-positive microbes, and when expressed in pathogens, are responsible for virulence.

Queries for T7SS genes homologous to genes in Mycobacterium tuberculosis and Staphylococcus aureus yielded no hits in Dietzia strains. However, type VII secretion systems are found in bacteria that are not pathogens, for example, in model organisms such as Bacillus subtilis. Because they are less complex than those of $M$. tuberculosis or S. aureus, these systems are called Type VIIb secretion systems to distinguish them from the mycobacterial T7SS (Unnikrishnan et al., 2017). We queried the genomes of four plant-growth promoting bacteria namely, $B$. subtilis $30 \mathrm{VD}-1$ and $B$. simplex $30 \mathrm{~N}-5$ for the presence of genes related to virulence. Both $B$. subtilis and $B$. simplex have a Type VIIb secretion system, which in B. subtilis 30VD-1 consists of 7 genes in contrast to the 20 different genes making up the Mycobacterium T7SS operon. The yuk genes encode an FtsK-SpoIIIE Atpase, WXG100 proteins, as well as other system-specific proteins.

Dietzia was found to be similar to Rhodococcus equi in several morphological traits (Koerner et al., 2009) and until the genus Dietiza was proposed by Rainey et al. (1995), many strains, both pathogenic and non-pathogenic, were named Rhodococcus (Yassin et al., 2006). Most genes related to virulence found in the environmental, non-pathogenic strains of Actinobacteria are conserved in the phyla, suggesting that pathogenicity is linked to certain acquired genes that trigger virulence (Letek et al., 2010). Given this scenario, we looked for genes in the Dietzia cinnamea strain 55 genome that were relevant to the pathogenicity of Rhodoccocus equi and Mycobacterium tuberculosis, species related to Dietzia.

Virulence-associated protein A (VapA) is a protein encoded by a gene on a plasmid that is linked to pathogenicity in $R$. equi. Two polymorphic forms of the gene were found depending on PCR amplification from either virulent or environmental samples suggesting an important role of this protein in disease (Kalinowski et al., 2018). However, this gene was not detected in strain 55, implying a lack of virulence. Also, $R$. equi possesses six $m m p L$ genes, encoding members of the "mycobacterial membrane protein large" family of transmembrane proteins, which are involved in complex lipid and surface-exposed polyketide secretion, cell wall biogenesis and virulence (Letek et al., 2010). Some non-pathogenic genera such as Micromonospora contain homologous genes, and Dietzia 

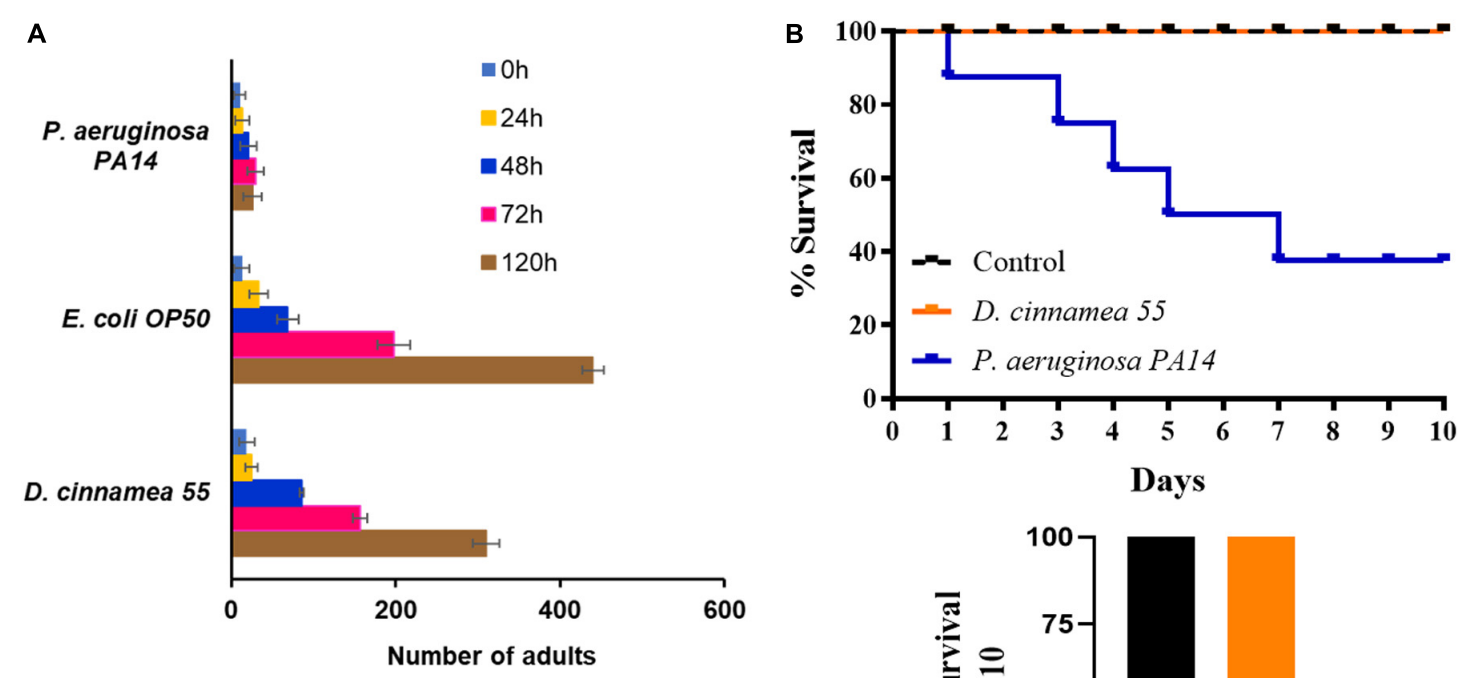

C
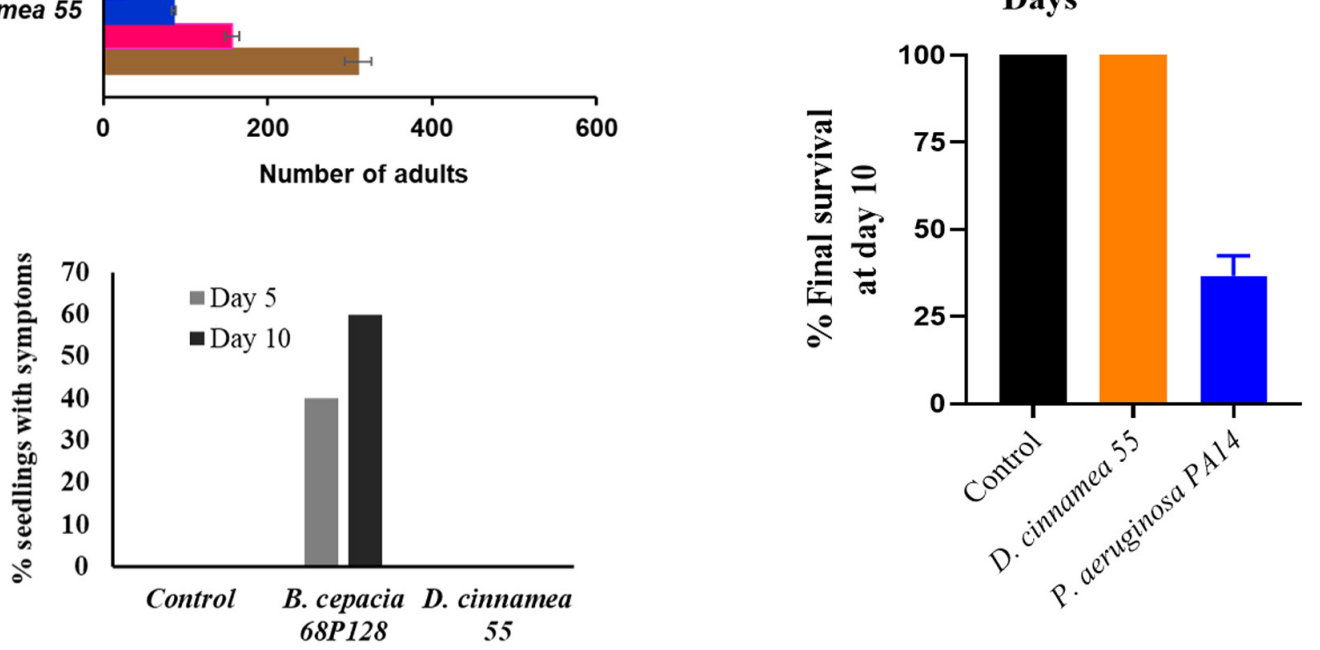

FIGURE 4 | Pathogenicity response of $D$. cinnamea 55. (A) Response of C. elegans fed with $D$. cinnamea 55 under slow-killing conditions. (B) Comparison of percent survival of $G$. mellonella after infection with $P$. aeruginosa PA14 and D. cinnamea 55. (C) Effect of $D$. cinnamea 55 inoculation on visual symptoms of pathology on alfalfa. B. cepacia 68P128 treatment served as the pathogen control. Values presented as mean \pm SD.

cinnamea 55 has at least two of them: JGI id: 650236657, a superfamily putative drug exporter and the integral membrane protein mmpl5 (JGI id: 650237246).

There are also four Fbp/antigen 85 homologs (REQ01990, 02000, 08890, 20840), involved in Mtb virulence as fibronectinbinding proteins and through their mycolyltransferase activity, are required for cord factor formation and integrity of the bacterial envelope (Letek et al., 2010). REQ01990 is not found in strain 55, and homolog 02000 (IS3 family transposase, partial), is a transposase but with only $50 \%$ identity to the Mycobacterium gene. The 08890 signal recognition particle-docking protein FtsY (Mycobacterium tuberculosis; gene ID 2786722813) has a higher identity, of $74 \%$ with a gene of the same name in strain 55, i.e., a signal recognition particle-docking protein Fts $\mathrm{Y}$ (gene ID 2786719992).

\section{DISCUSSION}

Global climate change has accelerated the concurrence of a variety of abiotic and biotic stress factors with adverse effects on agricultural productivity (Battisti and Naylor, 2009; Jin et al., 2017; Meyers et al., 2017). A sustainable solution to this problem is through the use of root-associated microbes, which consist of numerous plant beneficial bacteria. The PGPB present an alternate technology for improving the stress tolerance capacity of plants (Khan et al., 2011; Gamalero and Glick, 2015; Vejan et al., 2016). We hypothesized that such bacteria were potential candidates for promoting plant growth and proceeded to isolate bacteria from under the canopies of indigenous plants living in the Negev Desert (Kaplan et al., 2013).

We chose corn as a test plant because it is an important crop in American agriculture and faces a potential threat in production due to changing environmental conditions (Schlenker and Roberts, 2009; Jin et al., 2017). A steadfast endeavor toward improving farming technology and management strategies as well as more basic research in agricultural microbes is needed for reducing the negative impact of climate change and its anticipated effects on corn yield. The present study demonstrates how the inoculation of abiotic stress-tolerant $D$. cinnamea 55 enhanced the overall plant health of corn in comparison to untreated controls. A more robust and developed root system was observed in the bacteria-treated plants. Stimulation of root growth and effective root area for enhanced water and nutrient uptake is a very important stress management tool because a healthy and proliferated root system helps the plant maintain optimal growth and development under stress conditions (Mendes et al., 2013; Olanrewaju et al., 2019). Both greenhouse 
TABLE 4 | Plant beneficial function genes in D. cinnamea 55.

\begin{tabular}{|c|c|c|c|}
\hline IMG Gene ID & Locus tag & Gene product name & \\
\hline 2786721083 & Ga0193691_108131 & Cellulose synthase/poly-beta-1,6 N-acetylglucosamine synthase-like glycosyltransferase & Cellulase \\
\hline 2786719638 & Ga0193691_101129 & ATP-dependent Clp protease ATP-binding subunit CIpX & \multirow{18}{*}{ Protease } \\
\hline 2786719639 & Ga0193691_101130 & ATP-dependent Clp protease protease subunit & \\
\hline 2786719640 & Ga0193691_101131 & ATP-dependent Clp protease protease subunit & \\
\hline 2786719691 & Ga0193691_101182 & membrane associated rhomboid family serine protease & \\
\hline 2786719693 & Ga0193691_101184 & ATP-dependent Clp protease adaptor protein ClpS & \\
\hline 2786719965 & Ga0193691_102174 & RIP metalloprotease RseP & \\
\hline 2786720190 & Ga0193691_103165 & Protease I & \\
\hline 2786720720 & Ga0193691_10695 & CAAX prenyl protease-like protein & \\
\hline 2786720762 & Ga0193691_106137 & SI-C subfamily serine protease & \\
\hline 2786720830 & Ga0193691_10720 & Membrane associated rhomboid family serine protease & \\
\hline 2786720893 & Ga0193691_10783 & Putative intracellular protease/amidase & \\
\hline 2786720965 & Ga0193691_10813 & Membrane protease FtsH catalytic subunit & \\
\hline 2786720982 & Ga0193691_10830 & ATP-dependent Clp protease ATP-binding subunit CIpC & \\
\hline 2786721107 & Ga0193691_10917 & CAAX prenyl protease-like protein & \\
\hline 2786721437 & Ga0193691_11253 & ATP-dependent Clp protease ATP-binding subunit ClpB & \\
\hline 2786721792 & Ga0193691_11715 & putative serine protease PepD & \\
\hline 2786721889 & Ga0193691_1199 & Zn-dependent protease with chaperone function & \\
\hline 2786721992 & Ga0193691_1215 & CAAX prenyl protease-like protein & \\
\hline 2786721402 & Ga0193691_11218 & Catalase & \multirow{3}{*}{ Catalase } \\
\hline 2786722468 & Ga0193691_13235 & Mn-containing catalase & \\
\hline 2786722708 & Ga0193691_1426 & Catalase & \\
\hline 2786720149 & Ga0193691_103124 & Thiol peroxidase & \multirow{4}{*}{ Peroxidase } \\
\hline 2786721494 & Ga0193691_11328 & Glutathione peroxidase & \\
\hline 2786721948 & Ga0193691_12016 & Glutathione peroxidase & \\
\hline 2786720203 & Ga0193691_103178 & AhpD family alkylhydroperoxidase & \\
\hline 2786720208 & Ga0193691_103183 & Cu-Zn family superoxide dismutase & \multirow[t]{2}{*}{ Super oxide dismutase } \\
\hline 2786721118 & Ga0193691_10928 & Fe-Mn family superoxide dismutase & \\
\hline 2786720089 & GaO19369110363 & Osmoprotectant transport system permease protein & \multirow{5}{*}{ Osmoprotectant } \\
\hline 2786720090 & GaO193691_10364 & Osmoprotectant transport system ATP-binding protein & \\
\hline 2786720091 & GaO193691_10365 & Osmoprotectant transport system permease protein & \\
\hline 2786720092 & GaO193691_10366 & Osmoprotectant transport system substrate-binding protein & \\
\hline 2786720771 & GaO193691_106146 & Osmoprotectant transport system substrate-binding protein & \\
\hline 2786722800 & Ga0193691_1513 & General stress protein 26 & Stress tolerance \\
\hline 2786719696 & Ga0193691_101187 & NADPH-dependent ferric siderophore reductase & \multirow{5}{*}{ Siderophore } \\
\hline 2786720300 & GaO193691_10451 & NADPH-dependent ferric siderophore reductase & \\
\hline 2786720307 & Ga0193691_10458 & Siderophore synthetase component & \\
\hline 2786721468 & GaO193691_1132 & NADPH-dependent ferric siderophore reductase & \\
\hline 2786721697 & Ga0193691_11572 & NADPH-dependent ferric siderophore reductase & \\
\hline
\end{tabular}

and outside garden experiments showed that D. cinnamea strain 55 had growth-promoting effects on corn as measured by shoot and root dry weight and also ear size and dry weight.

We found no evidence for virulence factors in this novel Gram-positive actinomycete based on both genome analysis and experiments on C. elegans, G. mellonella, and plants. Our test results with alfalfa seedlings demonstrated the harmless nature of $D$. cinnamea 55 in comparison to phytopathogenic B. cepacia 68P128. The lack of defined virulence signatures for $D$. cinnamea 55 strongly suggests that it is not-pathogenic. Indeed, Dietzia natronolimnaea has been reported as a PGPB that protects wheat plants from salinity stress by regulating the expression of the plant's stress-responsive genes (Bharti et al., 2016). Other Dietzia strains have been used for bioremediation, for biosurfactants, bioemulsifiers, and carotenoid pigment production, and also as therapeutic probiotics for ruminant animals with paratuberculosis (Click and Van Kampen, 2010; Click, 2011; Procópio et al., 2012; Gharibzahedi et al., 2013). Nevertheless, some Dietzia strains have been reported to be opportunistic pathogens (Hirvonen et al., 2012), which is the reason we focused on searching for potential virulence factors in strain 55 .

Surprisingly we could not detect obvious PGPB genes for plant growth promotion such as those found in other PGPB 


\section{Dietzia cinnamea 55

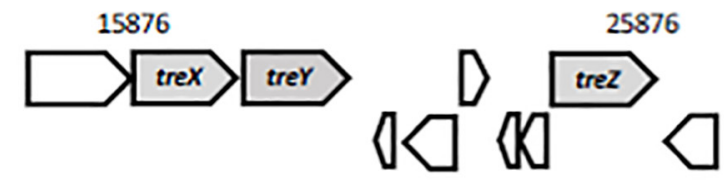

Micromonospora aurantiaca ATCC 27029

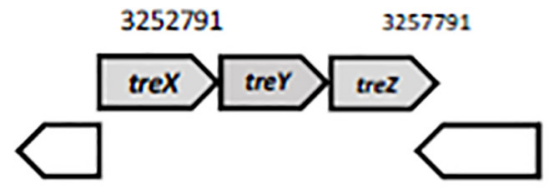

Micromonospora aurantiaca ATCC 27029

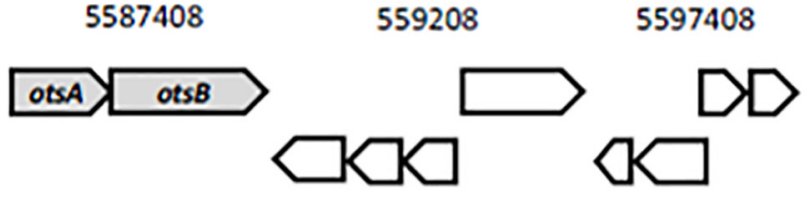

Dietzia cinnamea 55

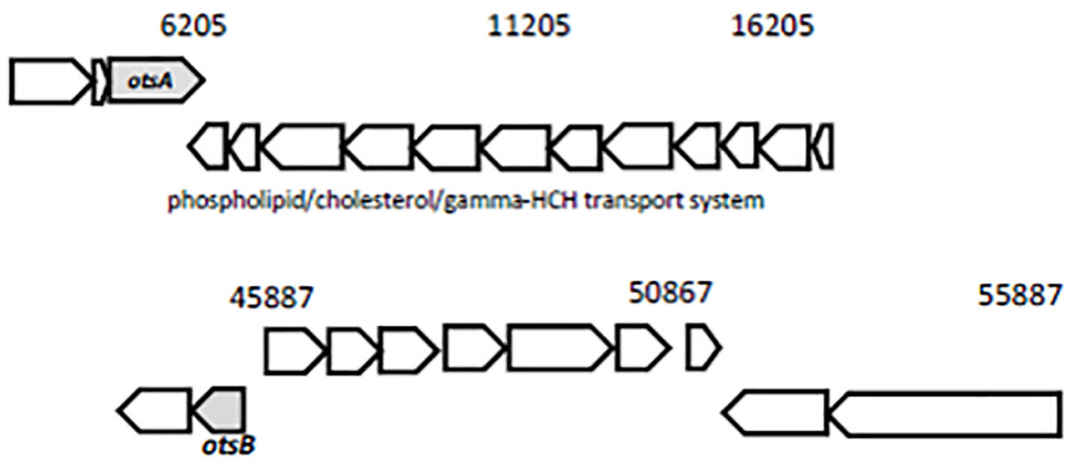

FIGURE 5 | Possible mechanisms of stress tolerance via trehalose accumulation in D. cinnamea 55. The treXYZ genes in D. cinnamea 55 and $M$. aurantiaca ATCC 27029, MOTS pathway. The ots $A$ and ots $B$ are together in an operon for $M$. aurantiaca ATCC 27029 whereas in $D$. cinnamea 55 , they are in two separate contigs, TPS pathway. The phospholipid/cholesterol/gamma-HCH transport gene system is shown for reference.

for phytohormone biosynthesis, other than the production of the polyamine spermidine, which interferes with ethylene biosynthesis (Maymon et al., 2015). Phosphate solubilization activity was not detected but siderophore production and also hydrolytic enzyme activity for potential entry into plant tissues were detected. However, strain 55 was not isolated from plant tissues, suggesting that it is not an endophyte.
The lack of the evidence in this study for the most typical PGP genes may result in part because the D. cinnamea 55 genome is unfinished. Another possibility is that protection from abiotic stress as conferred by strain 55 is sufficient for promoting enhanced growth at a crucial time in plant development, the germination and establishment stages. We are investigating this 
hypothesis further and are testing $D$. cinnamea strain 55 on corn in a large-scale field study to verify its PGPB potential.

\section{DATA AVAILABILITY STATEMENT}

The datasets generated for this study are available on request to the corresponding author.

\section{AUTHOR CONTRIBUTIONS}

$\mathrm{AH}$ and $\mathrm{NK}$ were involved in planning and execution of the research, analysis and interpretation of the data, and writing the manuscript. PM-H gave guidance on the virulence experiments and helped with writing the manuscript. EH and MM contributed intellectual advice and edited the manuscript. DK contributed strains and intellectual support.

\section{FUNDING}

This study was funded in part by grants from the Sol Leshin Program for Ben Gurion University-UCLA Academic Cooperation to DK and $\mathrm{AH}$ and from the Shanbrom Family Foundation to AH. A CSP 1571 project from the DOE/JGI funded the genome sequencing of Dietiza cinnamea 55.

\section{REFERENCES}

Adhikari, A., Nandi, S., Bhattacharya, I., Roy, M. D., Mandal, T., and Dutta, S. (2015). Phylogenetic analysis based evolutionary study of 16S rRNA in known Pseudomonas sp. Bioinformation 11, 474-480. doi: 10.6026/97320630011474

Angus, A. A., Agapakis, C. M., Fong, S., Yerrapragada, S., Estrada-de los Santos, P., Yang, P., et al. (2014). Plant-associated symbiotic Burkholderia species lack hallmark strategies required in mammalian pathogenesis. PLoS One 9:e83779. doi: 10.1371/journal.pone.0083779

Angus, A. A., Lee, A., Lum, M. R., Shehayeb, M., Hessabi, R., Fujishige, N. A., et al. (2013). Nodulation and effective nitrogen fixation of Macroptilium atropurpureum (siratro) by Burkholderia tuberum, a nodulating and plant growth promoting beta-proteobacterium, are influenced by environmental factors. Plant Soil 369, 543-562.

Backer, R., Rokem, J. S., Ilangumaran, G., Lamont, J., Praslickova, D., Ricci, E., et al. (2018). Plant growth-promoting rhizobacteria: context, mechanisms of action, and roadmap to commercialization of biostimulants for sustainable agriculture. Front Plant Sci. 9:1473. doi: 10.3389/fpls.2018.01473

Battisti, D. S., and Naylor, R. L. (2009). Historical warnings of future food insecurity with unprecedented seasonal heat. Science 323, 240-244. doi: 10.1126/science. 1164363

Bernier, S. P., Silo-Sah, L., Woods, D. E., Ohman, D. E., and Sokol, P. S. (2003). Comparative studies of plant and animal models for characterization of Burkholderia cepacia virulence. Infect. Immun. 71, 5306-5313. doi: 10.1128/ iai.71.9.5306-5313.2003

Bharti, N., Pandey, S. S., Barnawal, D., Patel, V. K., and Kalra, A. (2016). Plant growth promoting rhizobacteria Dietzia natronolimnaea modulates the expression of stress responsive genes providing protection of wheat from salinity stress. Sci. Rep. 6:34768. doi: 10.1038/srep34768

Brenner, S. (1974). The genetics of Caenorhabditis elegans. Genetics 77, 71-94.

Butler, E. E., Mueller, N. D., and Huybers, P. (2018). Peculiarly pleasant weather for US maize. Proc. Natl. Acad. Sci. U.S.A. 115, 11935-11940. doi: 10.1073/ pnas. 1808035115

\section{ACKNOWLEDGMENTS}

The contributions of Marcel Huntemann, Alicia Clum, Brian Foster, Bryce Foster, Simon Roux, Krishnaveni Palaniappan, Neha Varghese, Supratim Mukherjee, T. B. K. Reddy, Chris Daum, Alex Copeland, Natalia N. Ivanova, Nikos C. Kyrpides, Nicole Shapiro, and Emiley A. Eloe-Fadrosh of the Joint Genome Institute (Lawrence Berkeley National Laboratory) are acknowledged. Several UCLA undergraduates, Camille Carmona, Shayal Pratap, and Sophia Mohammadi, are also thanked for their help with the plant growth promotion assays. Lastly, we acknowledge the contributions of the late Dr. Yoav Bashan, a leader in the field of PGPB. He inspired us to pursue research in using microbes for soil restoration.

\section{SUPPLEMENTARY MATERIAL}

The Supplementary Material for this article can be found online at: https://www.frontiersin.org/articles/10.3389/fmicb. 2020.01149/full\#supplementary-material

FIGURE S1 | Salt (A) and PEG-induced drought (B) stress tolerance of D. cinnamea 55 .

FIGURE S2 | Photographs of siderophore production, and xylanase and cellulase activity of $D$. cinnamea 55 .

FIGURE S3 | Photographs of Galleria mellonella assay plates (i), and alfalfa plants (ii) treated with $D$. cinnamea 55.

Cardona, S. T., Wopperer, J., Eberl, L., and Valvano, M. A. (2005). Diverse pathogenicity of Burkholderia cepacia complex strains in the Caenorhabditis elegans host model. FEMS Microbiol. Lett. 250, 97-104. doi: 10.1016/j.femsle. 2005.06.050

Click, R. E. (2011). A 60-day probiotic protocol with Dietzia subsp. C7979374 prevents development of Johne's disease parameters after in utero and/or neonatal MAP infection. Virulence 2, 337-347. doi: 10.4161/viru.2.4. 16137

Click, R. E., and Van Kampen, C. L. (2010). Assessment of Dietzia subsp. C7979374 for treatment of cattle with evidence of paratuberculosis. Virulence 1-3, 145-155. doi: 10.4161/viru.1.3.10897

Estrada-de los Santos, P., Palmer, M., Chávez-Ramírez, B., Beukes, C., Steenkamp, E. T., Briscoe, L., et al. (2018). Whole genome analyses suggests that Burkholderia sensu lato contains two additional novel genera (Mycetohabitans gen. nov., and Trinickia gen. nov.): implications for the evolution of diazotrophy and nodulation in the Burkholderiaceae. Genes 9:389. doi: 10.3390/ genes 9080389

Farooq, M., Hussain, M., Wakeel, A., and Siddique, K. H. M. (2015). Salt stress in maize: effects, resistance mechanisms, and management. A review. Agron. Sustain. Dev. 35, 461-481.

Gamalero, E., and Glick, B. R. (2015). Bacterial modulation of plant ethylene levels. Plant Physiol. 169, 13-22. doi: 10.1104/pp.15.00284

Gharibzahedi, S. M. T., Razavi, S. H., and Mousavi, S. M. (2013). Characterization of bacteria of the genus Dietzia: an updated review. Ann. Microbiol. 64, 1-11. doi: 10.1007/s13213-013-0603-603

Hirsch, A. M., Alvarado, J., Bruce, D., Chertkov, O., De Hoff, P. L., Detter, J. C., et al. (2013). Complete genome sequence of micromonospora strain L5, a potential plant-growth-regulating actinomycete, originally isolated from Casuarina equisetifolia root nodules. Genome Announc. 1:e00759-13. doi: 10. 1128/genomeA.00759-13

Hirvonen, J. J., Lepistö, I., Mero, S., and Kaukoranta, S. S. (2012). First isolation of Dietzia cinnamea from a dog bite wound in an adult patient. J. Clin. Microbiol. 50, 4163-4165. doi: 10.1128/JCM.01939-12 
Hu, Q., and Buyanovsky, G. (2003). Climate effects on corn yield in Missouri. J. Appl. Meteorol. 42, 1626-1635.

Iqbal, M. N., Rasheed, R., Ashraf, M. Y., Ashraf, M. A., and Hussain, I. (2018). Exogenously applied zinc and copper mitigate salinity effect in maize (Zea mays L.) by improving key physiological and biochemical attributes. Environ. Sci. Pollut. R. 25, 23883-23896. doi: 10.1007/s11356-018-2383-6

Jander, G., Rahme, L. G., and Ausubel, F. M. (2000). Positive correlation between virulence of Pseudomonas aeruginosa mutants in mice and insects. J. Bacteriol. 182, 3843-3845. doi: $10.1128 /$ jb.182.13.3843-3845.2000

Jin, Z., Zhuang, Q., Wang, J., Archontoulis, S. V., Zobel, Z., and Kotamarthi, V. R. (2017). The combined and separate impacts of climate extremes on the current and future US rainfed maize and soybean production under elevated $\mathrm{CO} 2$. Glob. Chang. Biol. 23, 2687-2704. doi: 10.1111/gcb.13617

Joyce, S. A., and Gahan, C. G. M. (2010). Molecular pathogenesis of Listeria monocytogenes in the alternative model host Galleria mellonella. Microbiology 156, 3456-3468. doi: 10.1099/mic.0.040782-0

Kalinowski, M., Grądzki, Z., Jarosz, Ł, and Adaszek, Ł (2018). Molecular analysis of the chromosomal 16S rRNA gene and vapA plasmid gene of Polish field strains of R. equi. PLoS One 13:e0204024. doi: 10.1371/journal.pone. 0204024

Kaplan, D., Maymon, M., Agapakis, C. M., Lee, A., Wang, A., Prigge, B. A., et al. (2013). A survey of the microbial community in the rhizosphere of two dominant shrubs of the Negev Desert highlands, Zygophyllum dumosum (Zygophyllaceae) and Atriplex halimus (Amaranthaceae), using cultivationdependent and cultivation-independent methods. Am. J. Bot. 100, 1713-1725. doi: $10.3732 /$ ajb.1200615

Khan, N., Martínez-Hidalgo, P., Ice, T. A., Maymon, M., Humm, E. A., Nejat, N., et al. (2018). Antifungal activity of Bacillus species against fusarium and analysis of the potential mechanisms used in biocontrol. Front. Microbiol. 9:2363. doi: 10.3389/fmicb.2018.02363

Khan, N., Mishra, A., Chauhan, P., and Nautiyal, C. S. (2011). Induction of Paenibacillus lentimorbus biofilm by sodium alginate and $\mathrm{CaCl} 2$ alleviates drought stress in chickpea. Ann. Appl. Biol. 159, 372-386. doi: 10.1111/j.17447348.2011.00502.x

Koerner, R. J., Goodfellow, M., and Jones, A. L. (2009). The genus Dietzia: a new home for some known and emerging opportunist pathogens. FEMS Immunol. Med.l Mic. 55, 296-305. doi: 10.1111/j.1574-695X.2008.00513.x

Lange, A., Schäfer, A., Bender, A., Steimle, A., Beier, S., Parusel, R., et al. (2018). Galleria mellonella: a novel invertebrate model to distinguish intestinal symbionts from pathobionts. Front. Immun. 9:2114. doi: 10.3389/fimmu.2018. 02114

Letek, M., Gonzalez, P., MacArthur, I., Rodríguez, H., Freeman, T. C., ValeroRello, A., et al. (2010). The genome of a pathogenic Rhodococcus: cooptive virulence underpinned by key gene acquisitions. PLoS Genet. 6:e1001145. doi: 10.1371/journal.pgen.1001145

Lobell, D. B., Hammer, G. L., McLean, G., Messina, C., Roberts, M. J., and Schlenker, W. (2013). The critical role of extreme heat for maize production in the United States. Nat. Clim. Change 3, 497-501.

Martínez-Hidalgo, P., Maymon, M., Pule-Meulenberg, F., and Hirsch, A. M. (2018). Engineering root microbiomes for healthier crops and soils using beneficial, environmentally safe bacteria. Can. J. Microbiol. 65, 91-104. doi: 10.1139/cjm-2018-0315

Maymon, M., Martínez-Hidalgo, P., Tran, S. S., Ice, T., Craemer, K., Anbarachian, T., et al. (2015). Mining the phytomicrobiome to understand how bacterial coinoculations enhance plant growth. Front. Plant Sci. 6:784. doi: 10.3389/fpls. 2015.00784

Mendes, R., Garbeva, P., and Raaijmakers, J. M. (2013). The rhizosphere microbiome: significance of plant beneficial, plant pathogenic, and human pathogenic microorganisms. FEMS Microbiol. Rev. 37, 634-663. doi: 10.1111/ 1574-6976.12028

Meyers, S. S., Smith, M. R., Guth, S., Golden, C. D., Vaitla, B., Mueller, N. D., et al. (2017). Climate change and global food systems: potential impacts on food security and undernutrition. Ann. Rev. Publ. Health 38, 259-277. doi: 10.1146/annurev-publhealth-031816-044356

Mishra, S., and Nautiyal, C. S. (2012). Reducing the allelopathic effect of Parthenium hysterophorus L. on wheat (Triticum aestivum L.) by Pseudomonas putida. Plant Growth Regul. 66, 155-165.
Nautiyal, C. S., Mehta, S., and Singh, H. B. (2006). Biological control and plant growth promoting Bacillus strains from milk. J. Microb. Biotechnol. 16, 184-192.

Olanrewaju, O. S., Ayangbenro, A. S., Glick, B. R., and Babalola, O. O. (2019). Plant health: feedback effect of root exudates-rhizobiome interactions. Appl. Microbiol. Biotechnol. 103, 1155-1166. doi: 10.1007/s00253-018-9556-6

Prasad, R., Gunn, S. K., Rotz, C. A., Karsten, H., Roth, G., Buda, A., et al. (2018). Projected climate and agronomic implications for corn production in the Northeastern United States. PLoS One 13:e0198623. doi: 10.1371/journal.pone. 0198623

Procópio, L., Alvarez, V. M., Jurelevicius, D. A., Hansen, L., Sørensen, S. J. Cardoso, J., et al. (2012). Insight from the draft genome of Dietzia cinnamea P4 reveals mechanisms of survival in complex tropical soil habitats and biotechnology potential. Antonie Leeuwenhoek 101, 289-302. doi: 10.1007/ s10482-011-9633-7

$\mathrm{Pu}, \mathrm{M}$., and Rowe-Magnus, D. A. (2018). A Tad pilus promotes the establishment and resistance of Vibrio vulnificus biofilms to mechanical clearance. NPJ Biofilms Microbiomes 4:10. doi: 10.1038/s41522-018-0052-7

Rainey, F. A., Klatte, S., Kroppenstedt, R. M., and Stackebrandt, E. (1995). Dietzia, a new genus including Dietzia maris comb. nov., formerly Rhodococcus maris. Int. J. Syst. Bacteriol. 45, 32-36. doi: 10.1099/00207713-45-1-32

Schlenker, W., and Roberts, M. J. (2009). Nonlinear temperature effects indicate severe damages to U.S. crop yields under climate change. Proc. Natl. Acad. Sci. U.S.A. 106, 15594-15598. doi: 10.1073/pnas.0906865106

Schwartz, A. R., Ortiz, I., Maymon, M., Herbold, C. W., Fujishige, N. A., Vijanderan, J. A., et al. (2013). Bacillus simplex-A little known PGPB with anti-fungal activity alters pea legume root architecture and nodule morphology when coinoculated with Rhizobium leguminosarum bv. viciae. Agronomy 3, 595-620.

Streeter, J. G., and Gomez, M. L. (2006). Three enzymes for trehalose synthesis in Bradyrhizobium cultured bacteria and in bacteroids from soybean nodules. Appl. Environ. Microbiol. 72, 4250-4255. doi: 10.1128/AEM.00256-06

Timmusk, S., Behers, L., Muthoni, J., Muraya, A., and Aronsson, A. C. (2017). Perspectives and challenges of microbial application for crop improvement. Front. Plant Sci. 8:49. doi: 10.3389/fpls.2017.00049

Timmusk, S., Timmusk, K., and Behers, L. (2013). Rhizobacterial plant drought stress tolerance enhancement: towards sustainable water resource management and food security. J. Food Security 1, 6-9.

Unnikrishnan, M., Constantinidou, C., Palmer, T., and Pallen, M. J. (2017). The enigmatic Esx proteins: looking beyond mycobacteria. Trends Microbiol. 25, 192-204. doi: 10.1016/j.tim.2016.11.004

Vejan, P., Abdullah, R., Khadiran, T., Ismail, S., and Nasrulhaq Boyce, A. (2016). Role of plant growth promoting rhizobacteria in agricultural sustainability-a review. Molecules 21:573. doi: 10.3390/molecules21050573

Vílchez, J. I., Navas, A., Gonzalez-Lopez, J., Arcos, S. C., and Manzanera, M. (2016). Biosafety test for plant growth-promoting bacteria: proposed environmental and human safety index (EHSI) protocol. Front. Microbiol. 6:1514. doi: 10.3389/ fmicb.2015.01514

Weisburg, W. G., Barns, S. M., Pelletier, D. A., and Lane, D. J. (1991). 16 S ribosomal DNA amplification for phylogenetic study. J. Bacteriol. 173, 697-703. doi: 10.1128/jb.173.2.697-703.1991

Yassin, A. F., Hupfer, H., and Schaal, K. P. (2006). Dietzia cinnamea sp. nov., a novel species isolated from a perianal swab of a patient with a bone marrow transplant. Int. J. Syst. Evol. Microbiol. 56, 641-645. doi: 10.1099/ijs.0. 63863-0

Conflict of Interest: The authors declare that the research was conducted in the absence of any commercial or financial relationships that could be construed as a potential conflict of interest.

Copyright () 2020 Khan, Martínez-Hidalgo, Humm, Maymon, Kaplan and Hirsch. This is an open-access article distributed under the terms of the Creative Commons Attribution License (CC BY). The use, distribution or reproduction in other forums is permitted, provided the original author(s) and the copyright owner(s) are credited and that the original publication in this journal is cited, in accordance with accepted academic practice. No use, distribution or reproduction is permitted which does not comply with these terms. 